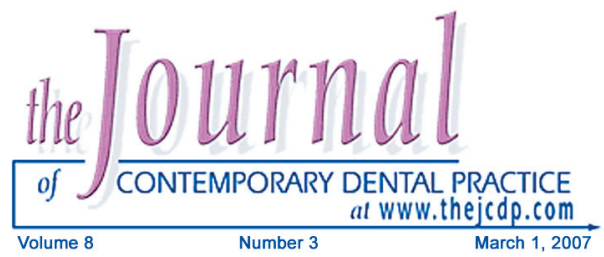

\title{
Tooth Size and Arch Dimension in Uncrowded Versus Crowded Class I Malocclusions
}

\section{Maryam Poosti, DDS; Tahereh Jalali, DDS, MSD}

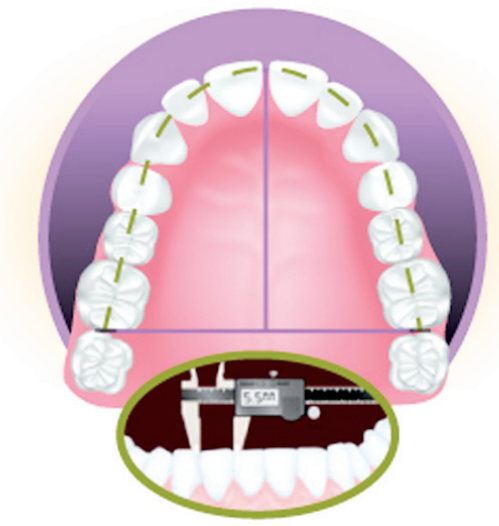

Abstract

Aim: The purpose of this investigation was to examine the extent to which arch dimension or tooth size contributes to dental crowding.

Methods and Materials: Two groups of dental casts were selected. Each group consisted of 30 pairs of dental casts including equal male and female samples. The first group had Class I malocclusions without crowding or spacing. The second group exhibited Class I malocclusions with severe dental crowding (> a $5 \mathrm{~mm}$ space deficiency). The following parameters were measured and used to compare the two groups: individual and collective mesiodistal tooth diameters, dental arch length, as well as buccal and lingual dental arch widths in the canine and molar regions. To compare the two groups the Student's t-test with $95 \%$ confidence interval was used.

Results: Statistically significant differences in both tooth diameters and transverse arch dimensions were found between the two groups. The crowded group was found to have a significantly smaller maxillary arch width and larger tooth size when compared with the uncrowded group.

Conclusion: The results of this study suggest under equal conditions (a Class I skeletal relationship) tooth size has a greater role in developing dental crowding.

Keywords: Tooth size, arch dimension, uncrowded dental arch, crowded dental arch

Citation: Poosti M, Jalali T. Tooth Size and Arch Dimension in Uncrowded Versus Crowded Class I Malocclusions. J Contemp Dent Pract 2007 March;(8)3:045-052.

(c) Seer Publishing 


\section{Introduction}

Dental crowding is the consequence of a tooth size-dental arch dimension discrepancy. Identifying the etiology of malocclusion has proven to be one of the most important issues in orthodontics. Different theories have tried to explain the etiology of dental crowding including hereditary and environmental factors.

The causes of malocclusions could be classified in two major categories, either dental or skeletal. One way of distinguishing between the two is to compare tooth size and arch dimensions in Class I occlusions with no crowding with Class I malocclusions exhibiting severe crowding. The results will reveal the dental or skeletal causes of crowding. This information will be helpful in treatment planning prior to orthodontic treatment.

Tooth size greatly differs among different races. ${ }^{3}$ In an investigation of tooth size of 139 Swedish boys in 1951, Lundstrom ${ }^{4}$ found crowding was greater in those individuals with larger teeth. The results of Fastlicht's ${ }^{5}$ studies were consistent with Lundstrom's and revealed a significant relationship between tooth size and crowding. In another study, Doris et al. ${ }^{6}$ found larger tooth sizes in crowded cases rather than in the noncrowded cases, with the greatest difference found between the maxillary lateral incisors and second premolars. Lombardi ${ }^{7}$ also found a significant relationship between mandibular tooth size and dental crowding following orthodontic treatment. On the other hand, in an investigation performed by Howe et al. ${ }^{8}$ comparisons were made between crowded and non-crowded groups using study models. They indicated arch dimension made a greater contribution to dental crowding than tooth size. Other investigators found the same correlation between arch dimensions and dental crowding. ${ }^{9-11}$

The purpose of this study was to examine the extent to which tooth size or arch dimensions contribute to dental crowding.

\section{Methods and Materials}

\section{Sample Selection}

This was a case control study using 60 pairs of study models divided into two groups. The first group consisted of 30 pairs of study models of

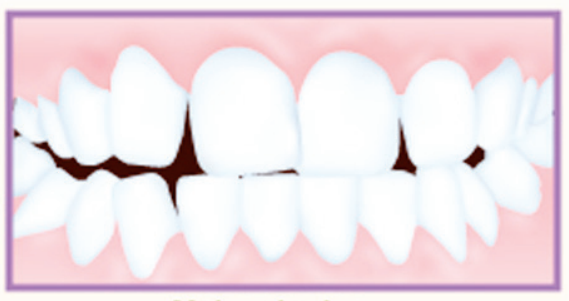

Malocclusion

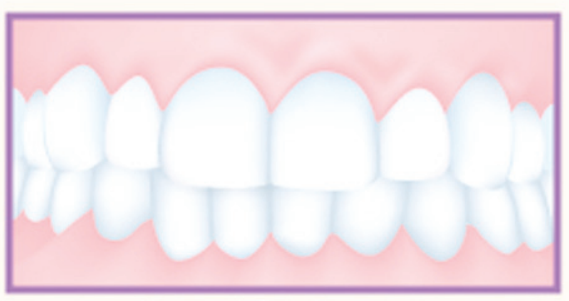

Normal Occlusion

Class I occlusions based on a Class I skeletal relationship without any abnormal spacing or crowding. The samples were divided evenly between the sexes (15 females and 15 males). These samples were selected from Mashhad University dental students. They all exhibited a straight profile, normal overbite and overjet, and Class I canine and molar relationships. The mean age of this group was $21.3 \pm 2.9$ years. The second group consisted of 30 pairs of study models of Class I malocclusions with a Class I skeletal base which had more than $5 \mathrm{~mm}$ of dental crowding. Again, the samples were equally divided between the sexes (15 males and 15 females) and were selected from patients who were referred to the Mashhad University Department of Orthodontics. The mean age of this group was $16.5 \pm 3.4$ years.

The selection of groups with the mean ages of the sample groups resulted in their active growth phase being behind them with very little growth that would affect the stability of the dental arches. The following characteristics were shared in both groups:

- All cases were in the permanent dentition with no missing or supernumerary teeth (excluding third molars).

- None of the teeth had proximal restorations.

- None had undergone any form of orthodontic treatment. 


\section{Measurements}

The following measurements were recorded:

- The largest mesiodistal width of each tooth (except the second and third molars) on each arch.

- Buccal and lingual inter-canine width.

- Buccal and lingual inter-molar width.

- Arch length.

- Perimeter of both arches.

- Anterior and overall Bolton ratios.

The mesiodistal widths of the teeth were measured in the largest area by calipers calibrated to $0.1 \mathrm{~mm}$. The caliper was held perpendicular to the tooth's long axis.

Arch dimensions in the canine and molar regions were measured buccally and lingually. The buccal arch dimension was measured $5 \mathrm{~mm}$ apical to the mesiodistal centre of the gingival margin of the canine tooth on one side to the same point on the contralateral side. On the lingual side, the distance between midpoint on the cervical region of the canine in one side was measured to the corresponding point on the contra-lateral side. ${ }^{8}$ The same procedure was performed in the molar region. The measurements were made by calipers calibrated to $0.1 \mathrm{~mm}$ (Figure 1).

The arch perimeter is a line drawn from the distal surface of the first permanent molar around the arch over the contact points and incisal edges in a smooth curve to the distal surfaces of the first permanent molars on the opposite side ${ }^{8,2} 0$ To draw the curve a clear glass slab was placed on the occlusal surface of the study casts with an acetate paper on the slab to facilitate the visibility of the teeth. Then the curve of the arch perimeter was drawn. The figures were scanned and the arch perimeters were measured using Auto-CAD ${ }^{\oplus}$ software (Autodesk, Inc., San Rafael, CA, USA) with $0.1 \mathrm{~mm}$ accuracy (Figure 2).

To determine the arch length a line was drawn from a point midway to the central incisors perpendicular to the tangent touching the distal surfaces of the first permanent molars. ${ }^{3,19}$ After drawing the arch perimeter with the same method described above, the distal surfaces of first molars were connected by a line and the

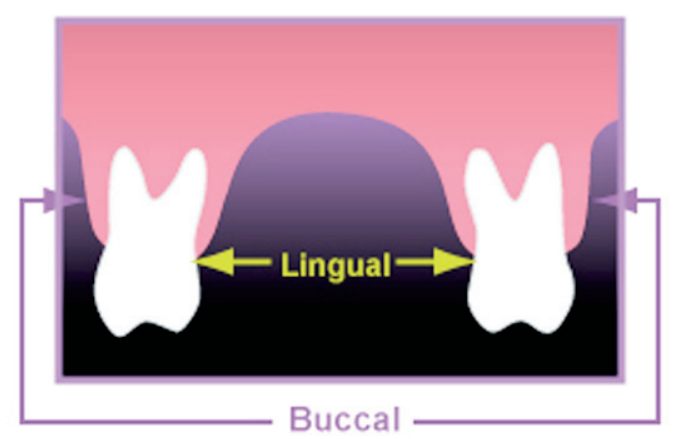

Figure 1. Buccal and lingual inter-molar width (Courtesy to Howe et al., Am J Orthod 1983.)

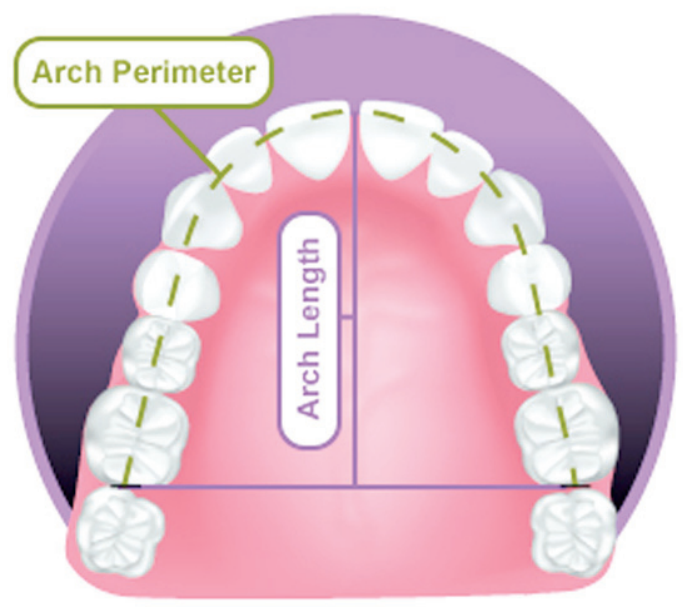

Figure 2. Arch perimeter and arch length.

arch length from midline between central incisors was drawn perpendicular to it. This line was measured within $0.1 \mathrm{~mm}$ accuracy (Figure 2). The data were analyzed using SPSS ${ }^{\circledR}$ software (SPSS Inc., Chicago, IL, USA), and the Student's t-test with a $95 \%$ confidence interval used to compare the two groups

\section{Results}

The comparison of tooth size between the normal and the crowded groups demonstrated the collective mesiodistal tooth diameters of both the 6 anterior as well as the 12 total teeth measured in both the maxilla and mandible were significantly greater in the crowded group than the normal group. This difference was observed in both males and females (Table 1).

When comparing individual teeth, the greatest difference was seen in the upper lateral incisors (Figures 3 and 4). 
Table 1. Collective mesiodistal tooth diameter, arch length, and arch perimeter for each sex in crowded and uncrowded occlusions ( $\mathrm{mm})$.

\begin{tabular}{|c|c|c|c|c|c|c|c|c|c|}
\hline \multirow{3}{*}{ Region } & \multicolumn{3}{|c|}{ Female $(n=30)$} & \multicolumn{3}{|c|}{ Male $(n=30)$} & \multicolumn{3}{|c|}{ Total $(n=60)$} \\
\hline & $\underset{n=15}{\text { Normal }}$ & $\begin{array}{c}\text { Crowded } \\
n=15\end{array}$ & \multirow[t]{2}{*}{$\mathbf{P}$} & $\underset{n=15}{\text { Normal }}$ & $\begin{array}{c}\text { Crowded } \\
n=15\end{array}$ & \multirow[t]{2}{*}{$\mathbf{P}$} & $\underset{n=15}{N}$ & $\begin{array}{c}\text { Crowded } \\
n=15\end{array}$ & \multirow[t]{2}{*}{$\mathbf{P}$} \\
\hline & Mean (SD) & Mean (SD) & & Mean (SD) & Mean (SD) & & Mean (SD) & Mean (SD) & \\
\hline $\begin{array}{l}\text { Sum of } 6 \text { Max. } \\
\text { Anteriors }\end{array}$ & 44.6 (1.91) & $48.5(2.44)$ & $<0.05$ & $46.0(1.44)$ & $48.4(2.00)$ & $<0.05$ & $45.3(1.83)$ & $48.4(2.19)$ & $<0.05$ \\
\hline $\begin{array}{l}\text { Sum of } 12 \text { Max. } \\
\text { teeth }\end{array}$ & $90.9(3.90)$ & $97.1(3.57)$ & $<0.05$ & $92.7(2.43)$ & $98.8(3.58)$ & $<0.05$ & $91.8(3.83)$ & $98.0(3.83)$ & $<0.05$ \\
\hline $\begin{array}{l}\text { Sum of } 6 \text { Mand. } \\
\text { Anteriors }\end{array}$ & $34.8(1.79)$ & $37.4(1.60)$ & $<0.05$ & $36.3(1.83)$ & $38.3(1.57)$ & $<0.05$ & $35.5(1.93)$ & $37.8(1.72)$ & $<0.05$ \\
\hline $\begin{array}{l}\text { Sum of } 12 \\
\text { Mand. teeth }\end{array}$ & $82.8(3.90)$ & $88.3(2.93)$ & $<0.05$ & $85.7(2.70)$ & 91.5 (3.71) & $<0.05$ & $84.2(3.60)$ & $89.9(3.67)$ & $<0.05$ \\
\hline $\begin{array}{l}\text { Max. Arch } \\
\text { Length }\end{array}$ & 35.7 (2.91) & $36.8(1.79)$ & NS & $37.0(2.00)$ & $37.2(2.22)$ & NS & $36.3(2.52)$ & $37.0(1.99)$ & NS \\
\hline $\begin{array}{l}\text { Max Arch } \\
\text { Perimeter }\end{array}$ & $97.3(6.05)$ & $96.9(3.60)$ & NS & $101.1(2.06)$ & $99.8(4.60)$ & NS & $99.2(4.84)$ & $98.3(4.33)$ & NS \\
\hline $\begin{array}{l}\text { Mand. Arch } \\
\text { Length }\end{array}$ & $32.3(2.44)$ & $31.3(1.78)$ & NS & $32.4(1.19)$ & $31.7(3.10)$ & NS & $32.3(1.89)$ & $31.3(2.54)$ & NS \\
\hline $\begin{array}{l}\text { Mand. Arch } \\
\text { Perimeter }\end{array}$ & $88.7(5.77)$ & $86.7(3.81)$ & NS & $90.5(1.91)$ & 89.1 (3.91) & NS & $89.6(4.32)$ & $87.9(3.99)$ & NS \\
\hline
\end{tabular}

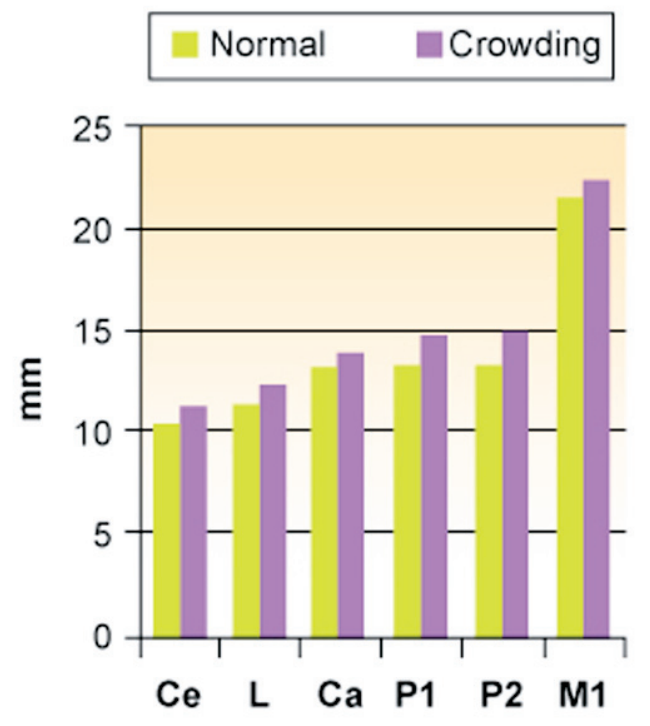

Figure 3. Collective mesiodistal tooth diameters for each pair of teeth (left and right).

In comparison of arch dimensions between the uncrowded and crowded groups the most significant difference in both sexes was the maxillary arch width of the canine and molar regions on both buccal and lingual aspects (Table 2). These dimensions were greater in the uncrowded group compared to the crowded group. However, the mandibular arch width did not show any significant difference between

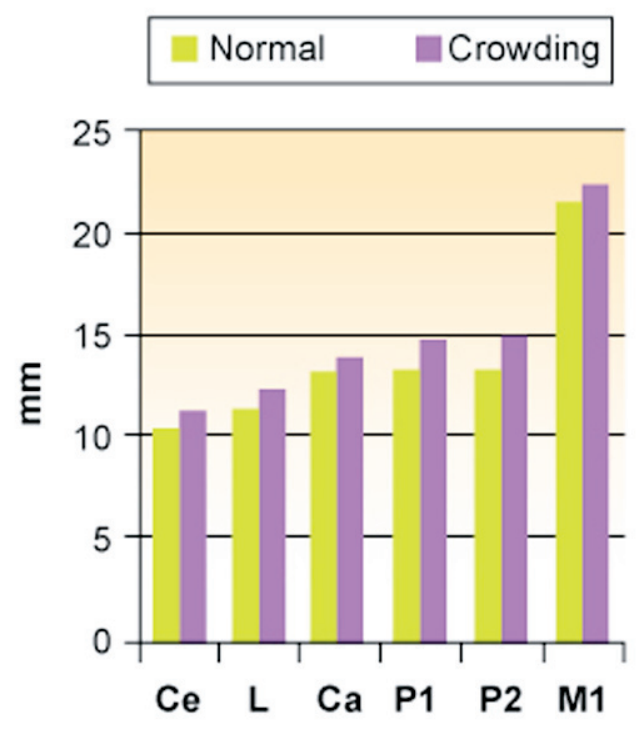

Figure 4. Collective mesiodistal tooth diameters of left and right mandibular teeth.

the two groups especially in the molar region (Table 3). There were no significant differences in either arch length or arch perimeter in the two groups in either the maxilla or the mandible (Table 1). In comparing the anterior and overall Bolton ratios no significant difference was detected between the crowded and uncrowded groups (Table 4). 
Table 2. Maxillary arch dimensions for each sex in crowded and uncrowded occlusions ( $\mathrm{mm}$ ).

\begin{tabular}{|c|c|c|c|c|c|c|c|c|c|}
\hline \multirow{3}{*}{ Region } & \multicolumn{3}{|c|}{ Female $(n=30)$} & \multicolumn{3}{|c|}{ Male $(n=30)$} & \multicolumn{3}{|c|}{ Total $(n=60)$} \\
\hline & $\begin{array}{c}\text { Normal } \\
n=15\end{array}$ & $\underset{n=30}{\text { Crowded }}$ & \multirow[t]{2}{*}{$\mathbf{P}$} & $\begin{array}{c}\text { Normal } \\
n=15\end{array}$ & $\underset{n=30}{\text { Crowded }}$ & \multirow[t]{2}{*}{$\mathbf{P}$} & $\begin{array}{c}\text { Normal } \\
n=30\end{array}$ & $\underset{n=30}{\text { Crowded }}$ & \multirow[t]{2}{*}{$\mathbf{P}$} \\
\hline & Mean (SD) & Mean (SD) & & Mean (SD) & Mean (SD) & & Mean (SD) & Mean (SD) & \\
\hline $\begin{array}{l}\text { Max Buccal } \\
\text { ICW } \dagger\end{array}$ & $37.3(1.79)$ & $34.8(1.97)$ & $<0.05$ & $38.8(3.26)$ & $35.7(2.24)$ & $<0.05$ & $38.1(2.69)$ & $35.2(2.12)$ & $<0.05$ \\
\hline $\begin{array}{l}\text { Max Lingual } \\
\text { ICW }\end{array}$ & $26.1(0.93)$ & $23.8(3.00)$ & $<0.05$ & $26.3(1.68)$ & $24.1(2.58)$ & NS & $25.7(1.34)$ & $23.9(2.94)$ & $<0.05$ \\
\hline $\begin{array}{l}\text { Max Buccal } \\
\text { IMW } \ddagger\end{array}$ & $59.0(2.09)$ & $56.9(2.61)$ & $<0.05$ & $60.9(2.36)$ & $57.9(2.57)$ & $<0.05$ & $59.9(2.38)$ & $57.9(2.57)$ & $<0.05$ \\
\hline $\begin{array}{l}\text { Max Lingual } \\
\text { IMW }\end{array}$ & $35.1(2.05)$ & $32.5(1.93)$ & $<0.05$ & $36.0(2.86)$ & $34.1(2.14)$ & $<0.05$ & $35.6(2.49)$ & $33.3(2.16)$ & $<0.05$ \\
\hline
\end{tabular}

† Intercanine Width $¥$ Intermolar Width NS - Not significant

Table 3. Mandibular arch dimensions for each sex in crowded and uncrowded occlusions (mm).

\begin{tabular}{|c|c|c|c|c|c|c|c|c|c|}
\hline \multirow{3}{*}{ Region } & \multicolumn{3}{|c|}{ Female $(n=30)$} & \multicolumn{3}{|c|}{ Male $(n=30)$} & \multicolumn{3}{|c|}{ Total $(n=60)$} \\
\hline & $\begin{array}{c}\text { Normal } \\
n=30\end{array}$ & $\begin{array}{c}\text { Crowded } \\
n=30\end{array}$ & \multirow[t]{2}{*}{$\mathbf{P}$} & $\begin{array}{c}\text { Normal } \\
n=30\end{array}$ & $\begin{array}{c}\text { Crowded } \\
n=30\end{array}$ & \multirow[t]{2}{*}{$\mathbf{P}$} & $\begin{array}{c}\text { Normal } \\
n=30\end{array}$ & $\begin{array}{c}\text { Crowded } \\
n=30\end{array}$ & \multirow[t]{2}{*}{$\mathbf{P}$} \\
\hline & Mean (SD) & Mean (SD) & & Mean (SD) & Mean (SD) & & Mean (SD) & Mean (SD) & \\
\hline $\begin{array}{l}\text { Mand. Buccal } \\
\text { ICW } \dagger\end{array}$ & $30.8(1.33)$ & $29.6(1.83)$ & $<0.05$ & $32.3(1.32)$ & $30.1(2.69)$ & $<0.05$ & $31.6(1.51)$ & $29.8(2.27)$ & $<0.05$ \\
\hline $\begin{array}{l}\text { Mand. Lingual } \\
\text { ICW }\end{array}$ & $19.1(0.86)$ & $19.0(2.80)$ & NS & $20.2(1.06$ & $20.0(1.60)$ & NS & $19.7(1.05)$ & $19.6(2.34)$ & NS \\
\hline $\begin{array}{l}\text { Mand. Buccal } \\
\text { IMW }\end{array}$ & $56.0(2.57)$ & $55.2(2.46)$ & NS & $58.6(2.09)$ & $58.6(3.33)$ & NS & $57.3(2.66)$ & $56.9(3.79)$ & NS \\
\hline $\begin{array}{l}\text { Mand. Lingual } \\
\text { IMW }\end{array}$ & $32.4(1.84)$ & $30.6(1.74)$ & NS & $33.5(2.26)$ & $32.6(4.01)$ & NS & $32.9(2.11)$ & $31.6(3.22)$ & NS \\
\hline
\end{tabular}

† Intercanine Width $¥$ Intermolar Width NS - Not significant

Table 4. Anterior and overall Bolton ratio for each sex in crowded and uncrowded occlusions.

\begin{tabular}{|c|c|c|c|c|c|c|c|c|c|}
\hline \multirow{3}{*}{ Region } & \multicolumn{3}{|c|}{ Female $(n=30)$} & \multicolumn{3}{|c|}{ Male $(n=30)$} & \multicolumn{3}{|c|}{ Total $(n=60)$} \\
\hline & $\begin{array}{c}\text { Normal } \\
n=30\end{array}$ & $\underset{n=30}{\text { Crowded }}$ & \multirow[t]{2}{*}{$\mathbf{P}$} & $\begin{array}{c}\text { Normal } \\
n=30\end{array}$ & $\begin{array}{c}\text { Crowded } \\
n=30\end{array}$ & \multirow[t]{2}{*}{$\mathbf{P}$} & $\begin{array}{c}\text { Normal } \\
n=30\end{array}$ & $\begin{array}{c}\text { Crowded } \\
n=30\end{array}$ & \multirow[t]{2}{*}{$\mathbf{P}$} \\
\hline & Mean (SD) & Mean (SD) & & Mean (SD) & Mean (SD) & & Mean (SD) & Mean (SD) & \\
\hline $\begin{array}{l}\text { Anterior Bolton } \\
\text { Ratio }\end{array}$ & $73.1(0.18)$ & $77.0(0.03)$ & NS & $78.8(0.03)$ & $79.1(0.02)$ & NS & $75.9(0.13)$ & $78.0(0.03)$ & NS \\
\hline $\begin{array}{l}\text { Overall Bolton } \\
\text { Ratio }\end{array}$ & $91.3(0.02)$ & $90.8(0.02)$ & NS & $92.3(0.02)$ & $92.5(0.01)$ & NS & $91.8(0.02)$ & $91.6(0.02)$ & NS \\
\hline
\end{tabular}

NS - Not significant

\section{Discussion}

The greater collective tooth diameter in six and 12 teeth in the maxilla and mandible in the crowded group of males and females corroborates with the results of Lundstrom, ${ }^{4}$ Fastlicht, ${ }^{5}$ Doris et al. ${ }^{6}$ and Lombardi. ${ }^{7}$ On the other hand, Howe' et al., Randzic ${ }^{9}$ Forsberg $^{10}$ and Gilmore ${ }^{11}$ did not find significant correlation between mesiodistal tooth size and crowding and concluded crowding was related to dental arch dimensions instead of tooth size. In the present study we found both smaller arch dimensions (especially in maxillary width) and greater tooth size in the crowded group, compared to the uncrowded samples.

In the study conducted by Howe' et al. the sample size of the crowded and uncrowded groups were not equal, and their ages ranged from 9 to 44 years old. In the present study the number of samples in the crowded and uncrowded groups were the same (each group contained 30 samples), and the number of males and females in each group were also equal (each 


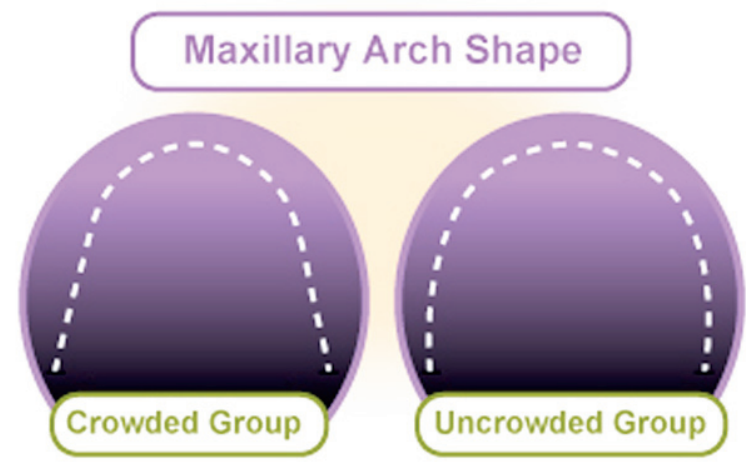

group included 15 boys and 15 girls). In addition, all of the samples had been chosen from young adults who were expected to have passed their active growth phase, and, therefore, had stable arch widths. In the present study both groups had Class I skeletal relationships. However, in previous studies ${ }^{8}$ the skeletal relationship was not included in the factors considered for the crowded group. This could affect arch dimensions in different malocclusions. In an article published by Gilmore ${ }^{11}$ studies were conducted on crowding that developed after orthodontic treatment.

However, in our study we examined patients who had never had previous orthodontic treatment. By evaluating arch dimensions in our study, the most significant difference was seen in maxillary arch width which was greater in the uncrowded group. However, there was no significant difference in maxillary arch length and arch perimeter between the two groups. Therefore, it could be concluded the uncrowded group has wider but not longer upper dental arches than the crowded group. Mandibular arch dimensions, both in the transverse and longitudinal directions, did not differ significantly between the uncrowded and crowded groups, except for the buccal intercanine width which was significantly greater in the uncrowded group. This may be due to prominent canine root areas in the uncrowded dentitions. In the majority of crowded mandibles the canine tooth is rotated and does not show a root prominence in the oral mucosa. The inference here is in crowded mandibles there are fewer options for non-extraction treatments.

On the other hand, the present research suggests a greater tooth size in the crowded group in comparison with the uncrowded one. This shows the limitations of non-extraction treatment protocols in crowded dental arches should be considered or one would have to face some unsuccessful instances of treating crowded dentitions by means of non-extraction protocols such as expansion, flaring the teeth, or distal repositioning of the molars. ${ }^{21-24}$ Henceforth, the need for tooth material reduction (extraction and stripping) in many cases should not be dismissed.

In comparing the anterior and overall Bolton ratio in crowded and uncrowded groups for each sex no significant difference was found. This indicates perhaps tooth size increases simultaneously in the upper and lower arches in the crowded group. Bernabe et al. ${ }^{25}$ found a statistically significant difference in tooth width ratios in crowded and noncrowded groups and also claimed this difference was too small to be considered of clinical significance.

\section{Conclusion}

The results of this study indicate under equal circumstances (Class I skeletal relationship of the jaws):

- Tooth size has a greater contribution to the development of dental crowding.

- Among different arch dimensions maxillary arch width was found to have the most significant difference between two groups.

- The Bolton ratio showed no significant difference in crowded and uncrowded groups. 


\section{References}

1. Proffit WR, Fields HW. Contemporary Orthodontics. 3rd ed. St. Louis: Mosby; 2000. P.108-110.

2. Graber TM, Vanarsdall IR. Orthodontics Current Principles and Techniques. 3rd ed. St. Louis: Mosby; 2000.P. 395-397, 408.

3. Moyers RE. Handbook of Orthodontics.3rd ed. Michigan:Yearbook Medical Publisher; 1988.P. 195-200.

4. Lundstrom A. The etiology of crowding of the teeth (based an studies of twins and on morphological investigations) and its bearing on orthodontic treatment (expansion or extraction). Tr. European Orthodont Soc $1951 ;$ 176-91.

5. Fastlicht J. Crowding of mandibular incisor. Am J Orthod 1970; 58: 156-63.

6. Doris JM, Bernard DW, Kuftinec MM. A biometric study of tooth size and dental crowding. Am J Orthod 1981; 79: 326-35.

7. Lombardi AR. Mandibular incisor crowding in completed cases. Am J Orthod 1972; 61: 374-91.

8. Howe' RP, McNamara JA, Oconnor K. An examination of dental crowding and its relationship to tooth size and arch dimension. Am J Orthod 1983; 83: 363-73.

9. Randzic D. Dental crowding and its relationship to mesiodistal crown diameters and arch dimension. Am J Orthod Dentofac Orthop 1988; 94: 50-56.

10. Forsberg CM. Tooth size and spacing in relation to eruption or impaction of third molars. Am J Orthod Dentofac Orthop 1988; 94: 57-61.

11. Gilmore CA, Little RM. Mandibular incisor dimensions and crowding. Am J Orthod 1984; 86 : 493-502.

12. Stanely B, Hnat WP, Fender DE, Legan HL. The form of the human dental arch. Angle Orthodontics 1998; 68: 29-35.

13. Bishara S, Jakobsen BA, Trede J, Nowak A. Arch width changes from 6 weeks to 45 years of age. Am J Orthod 1997; 111: 401-9.

14. Harris E. A longitudinal study of arch size and from in untreated adults. Am J Orthod Dentofac Orthop 1997; 111:419-27.

15. Sinclair P, Little RM. Maturation of untreated normal occlusions. Am J Orthod 1983; 83: 114-23.

16. Sillman JH. Dimensional changes of the dental arches: Longitudinal study from birth to 25 years. Am J Orthod 1961; 50: 824-41.

17. Shapiro PA. Mandibular dental arch form and dimension. Am J Orthod 1974; 66: 58-71.

18. Harris EF, Smith RJ. Occlusion and arch width in families. Am J Orthod 1980; 78: 155-63.

19. Hnat WP, Braun S, Chinhara A, Legan HL. The relationship of arch length to alterations in dentalarch width. Am J Orthod Dentofac Orthop 2000; 118: 184-88.

20. Miwthke RR, Behm-Menthel A. Correlations between lower incisor crowding and lowerincisor position and lateral cranial face morphology. Am J Orthod Dentofac Orthop 1988; 94: 231-39.

21. Keles A, Syinsu K. A new approach in maxillary molar distalization: Intra Oral bodily molar distalization. Am J Orthod Dentofac Orthop 2000; 117: 39-48.

22. Bussik TJ, McNamara JA. Dento alveolar and skeletal changes associated with Pendulum appliance. Am J Orthod Dentofac Orthop 2000; 117: 333-43.

23. Gianelly AA, Bendar J, Dietz VS. Japanese NiTi coils used to move molar distally. Am J Orthod Dentofac Orthop 1991; 99: 564-6.

24. Cetlin NM, TenHoeve A. Non extraction treatment. J Clin Orthod 1983; 17: 396-413.

25. Bernabe E, Villanueva KM, Flores-Mir C. Tooth width ratios in crowded and non crowded dntitions. Angle Orthod.2004; 74: 765-8. 
About the Authors

Maryam Poosti, DDS

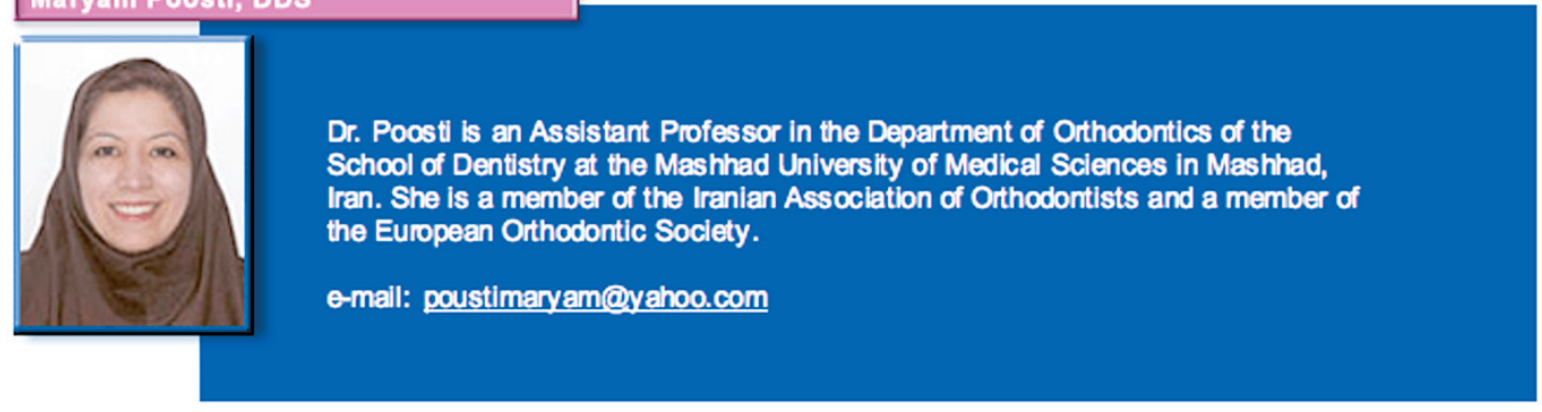

\section{Tahereh Jalall, DDS, MSD}

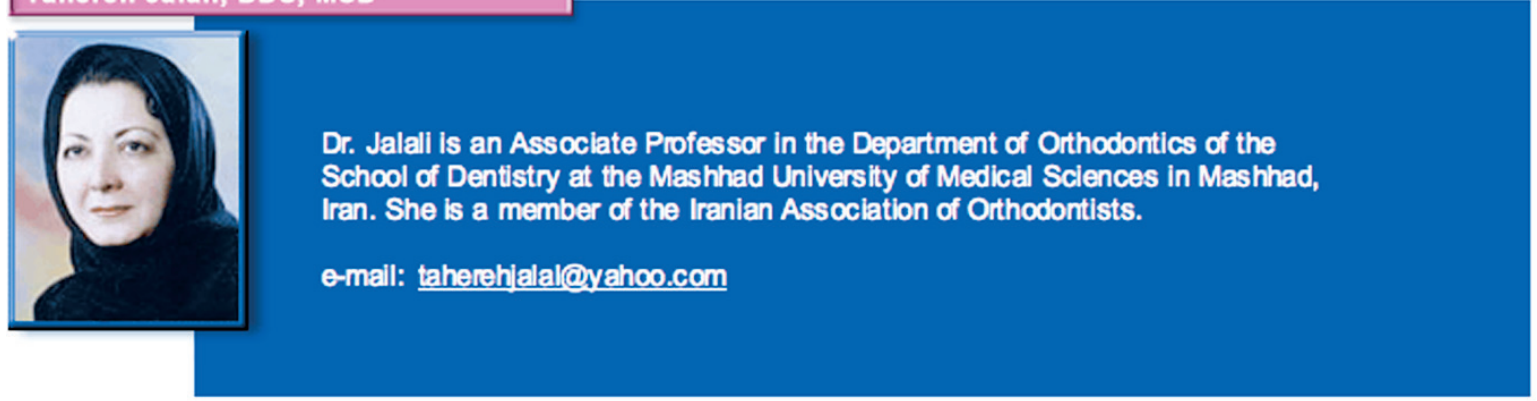

\section{Acknowledgement}

With special thanks to our dear friend Dr. Farnaz Parvizi who devoted a great deal of time assisting us with this manuscript. 